\title{
A CFD STUDY ON THE STRUCTURAL RESPONSE OF A SLOPING TOP CAISSON SUBJECT TO WAVE OVERTOPPING
}

\author{
Mohammad Daliri ${ }^{1}$, Fabio Dentale ${ }^{2}$, Daniela Salerno ${ }^{3}$ Mariano Buccino ${ }^{4}$ \\ The paper discusses preliminary results of a CFD study on the structural response of a Sloping Top Breakwater subject \\ to wave overtopping. The analysis showed that the transmitted wave field act to increase both the landward and the \\ seaward forces and that the conventional design methods may be not adequate to guarantee an appropriate degree of \\ safety to the structure. The study also confirmed the previous finding by Walkden et al. (2001), which noticed the \\ existence of strong impulsive loadings on the inner face of the wall, due to violent overtopping events.
}

Keywords: wave overtopping, sloping top caisson, impulsive waves, CFD modeling

\section{INTRODUCTION}

You Wave overtopping is a major process in the field of coastal engineering and a huge body of literature has been published, mainly with the aim of predicting the flux of water overpassing structures during a storm (EurOTOP, 2007). Traditionally, engineers design breakwaters to limit overtopping events, guaranteeing the tranquility of harbors. However, in some cases this phenomenon is instead favored and namely for wave energy converters which deploy the overtopping mechanism (Buccino et al., 2015a, 2015b, Contestabile et al., 2016) and in presence of wave attacks of particular severity. In the latter case, wave overtopping may reduce the magnitude of the wave action and, for vertical breakwaters, lower the probability of impulsive loadings (Goda 1995, Allsop et al., 1997, Calabrese and Buccino, 2000).

A monolithic structure expressly designed to face rough seas is the so-called "sloping top caisson", which feature a sloped superstructure over a vertical face body. Despite it has long been used in the engineering practice (the first was constructed in Naples, Italy, in 1906), detailed reports on their structural response are very few. In 1994, Takahashi et al. proposed a prediction method to calculate wave force under the crest phase, which modifies the well-known Goda formula for vertical walls. The method is based on few regular wave experiments in absence of overtopping and, at the authors knowledge, has been not further verified. On the other hand, Walkden et al. (2001) warned that when sloping top caissons undergo violent overtopping, intense impulsive loadings may occur on its rear face, which may lead the structure to slide seaward. Moreover, the authors suggested an approach based on the theory of Cooker and Peregrine (1995), to estimate the impulse of such rear pressures. Those findings, though, are supported by the observation of only three individual waves.

This paper discusses preliminary results of a numerical investigation conducted with the aim to have a deeper insight on the structural response of the sloping top caissons subjected to wave overtopping. Using 8 random sea states driven by extremely narrow banded spectra, the general characteristics of the hydrodynamic loadings are studied and the methods of Takahashi et al. (1994) and Walkden et al. (2001) are preliminarily verified.

The experiments discussed in the present study, have performed using the multi-physics CFD software FLOW-3D, developed by Flow Science Inc (2009); the numerical suite has been already successfully employed in a number of wave-structure interaction problems, including both impermeable walls and permeable breakwaters (e.g. Buccino et al., 2016; Vicinanza et al., 2015, Dentale et al., 2014a, 2014b). Conservation equations for mass and momentum are solved through the discretization of the Reynolds Averaged Navier-Stokes Equations (RANS). The free surface movement is tracked by the Volume of Fluid (VOF) method, which can be used in both single and two-phase modeling. For the present application, a Re-Normalization Group (RNG) k-epsilon turbulence closure has been chosen. A sketch of the experimental setup is illustrated in Figure 1. During the experiments, the water depth at the toe of the structure was kept constant at $18.9 \mathrm{~m}$; six wave probes were deployed seaward the caisson to separate incident and reflected, waves via the weighted least square approach proposed by Zelt and Skjelbreia (1992).

\footnotetext{
1 Department of Civil, Architectural and Environmental Engineering, University of Naples Federico II, Italy

2 Department of Civil Engineering, University of Salerno, Italy

3 Department of Civil Engineering, University of Salerno, Italy

${ }^{4}$ Department of Civil, Architectural and Environmental Engineering, University of Naples Federico II, Italy
} 


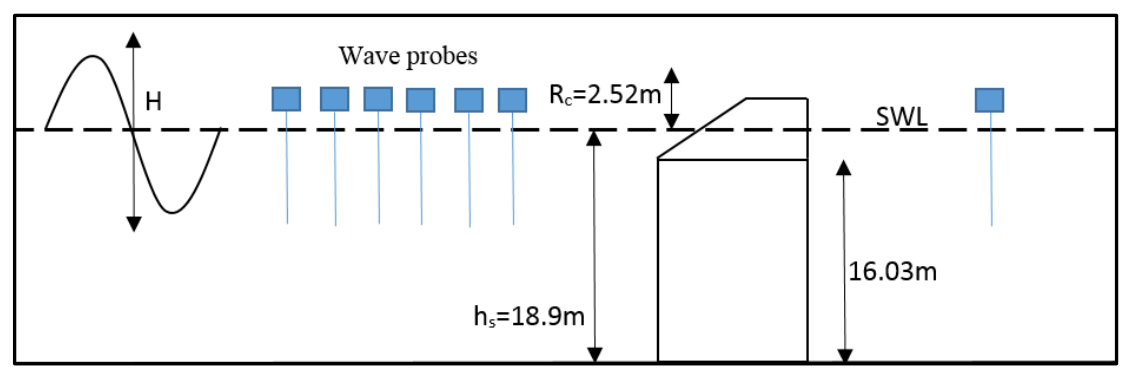

Figure 1. Sketch of the experimental set up.

8 sea-states were simulated, made up on 30 waves on average. The storms were driven by a very narrow banded spectrum, allowing to keep the wave period almost constant in each test. Wave parameters are summarized in Table 1, along with the sampling rate, $\Delta \mathrm{t}$, used for both waves and loadings. Tests from $1 \mathrm{~A}$ to $2 \mathrm{C}$ were carried out with single fluid (water without air entrainment), whereas $3 \mathrm{~A}, 3 \mathrm{~B}$ and $4 \mathrm{~A}$ used the two fluid model option of $F L O W-3 D$, in which the governing equations are solved for all the fluid cells (air and water) regardless of the fluid fraction. Wave pressure was recorded in 20 different positions along the caisson profile (10 in front and 10 behind), as depicted in Figure 2. Video recording of each experiment has been taken.

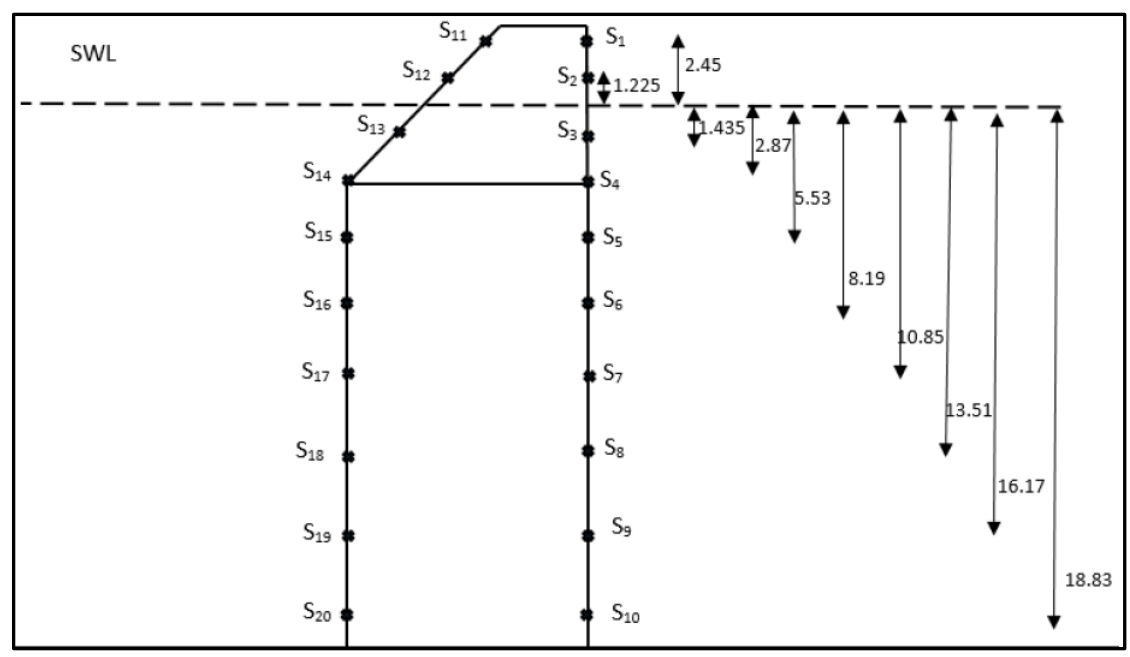

Figure 2. Positions of pressure transducers (unit: $\mathrm{m}$ ).

\section{RESULTS}

\section{Wave Shapes at Wall}

Steepest waves were observed to break either on the outer face of the wall (impact events) or slightly seaward (broken events). An example is given in Figure 3. Here, the incoming wave plunges into the water in the neighborhood of the slope; then, a wave reforms and a secondary plunging jet detaches from the crest (see Calabrese et al., 2008) and hits the wall during the uprush phase. Finally, the breakwater is overtopped. 


\begin{tabular}{|c|c|c|c|c|}
\hline \multicolumn{5}{|c|}{ Table 1. Summary of wave conditions. } \\
\hline TEST CODE & $\mathrm{H}_{\mathrm{s}}[\mathrm{m}]$ & $\mathrm{T}_{\mathrm{p}}[\mathrm{s}]$ & $\mathrm{R}_{\mathrm{c}} / \mathrm{Hs}$ & $\Delta \mathrm{t}[\mathrm{s}]$ \\
\hline 1A & 4.90 & 6.32 & 0.51 & 0.008 \\
1B & 3.65 & 6.41 & 0.69 & 0.008 \\
1C & 3.04 & 6.44 & 0.83 & 0.008 \\
2A & 5.58 & 11.56 & 0.45 & 0.015 \\
2C & 3.47 & 11.86 & 0.73 & 0.015 \\
3A & 7.08 & 11.89 & 0.36 & 0.008 \\
3B & 5.06 & 12.21 & 0.50 & 0.008 \\
4A & 6.21 & 6.74 & 0.41 & 0.004 \\
\hline
\end{tabular}

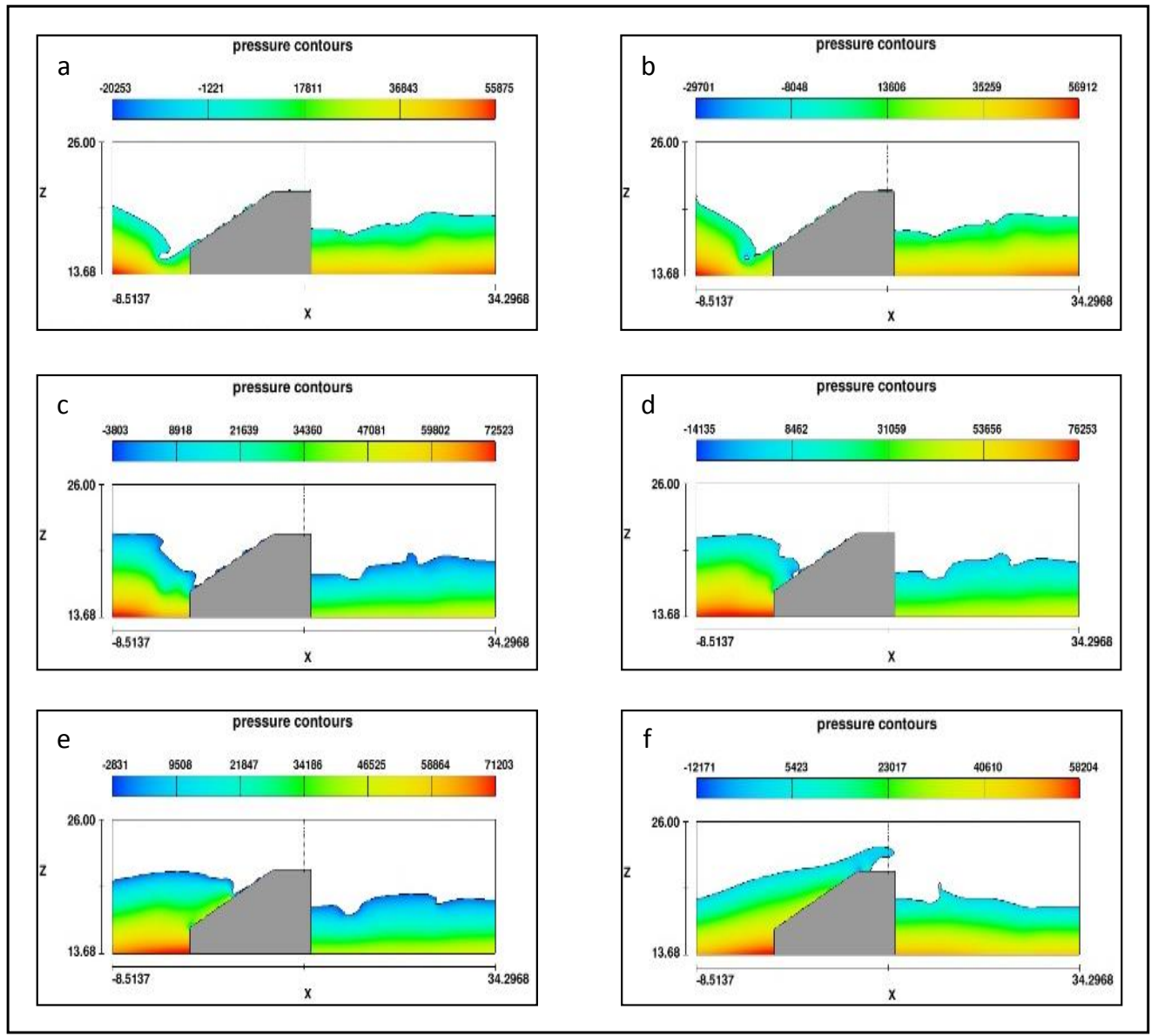

Figure 3. Example of broken event (Test 1A).

In the example of Figure 4, the main wave is seen to collapse, instead, directly on the caisson. With growing wave period, quasi standing waves/surging breakers are observed (Figure 5) that give rise to overtopping events without impact; in some cases, though, a small jet of fluid has been seen to form in the wave trough, slamming the breakwater in the juncture between the vertical face and the sloping top (upper panels of Figure 5). 


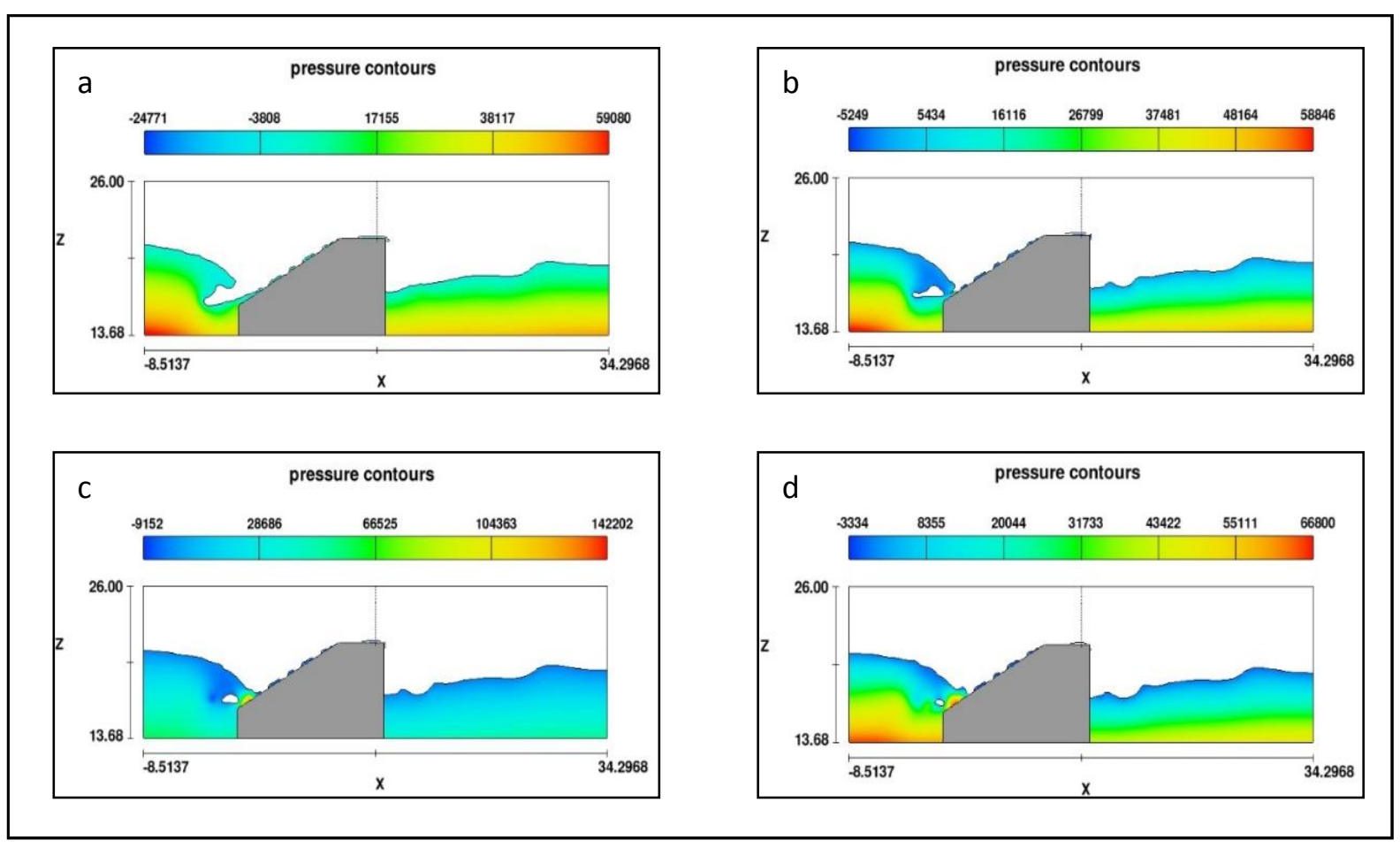

Figure 4. Example of impact event (Test 1A).
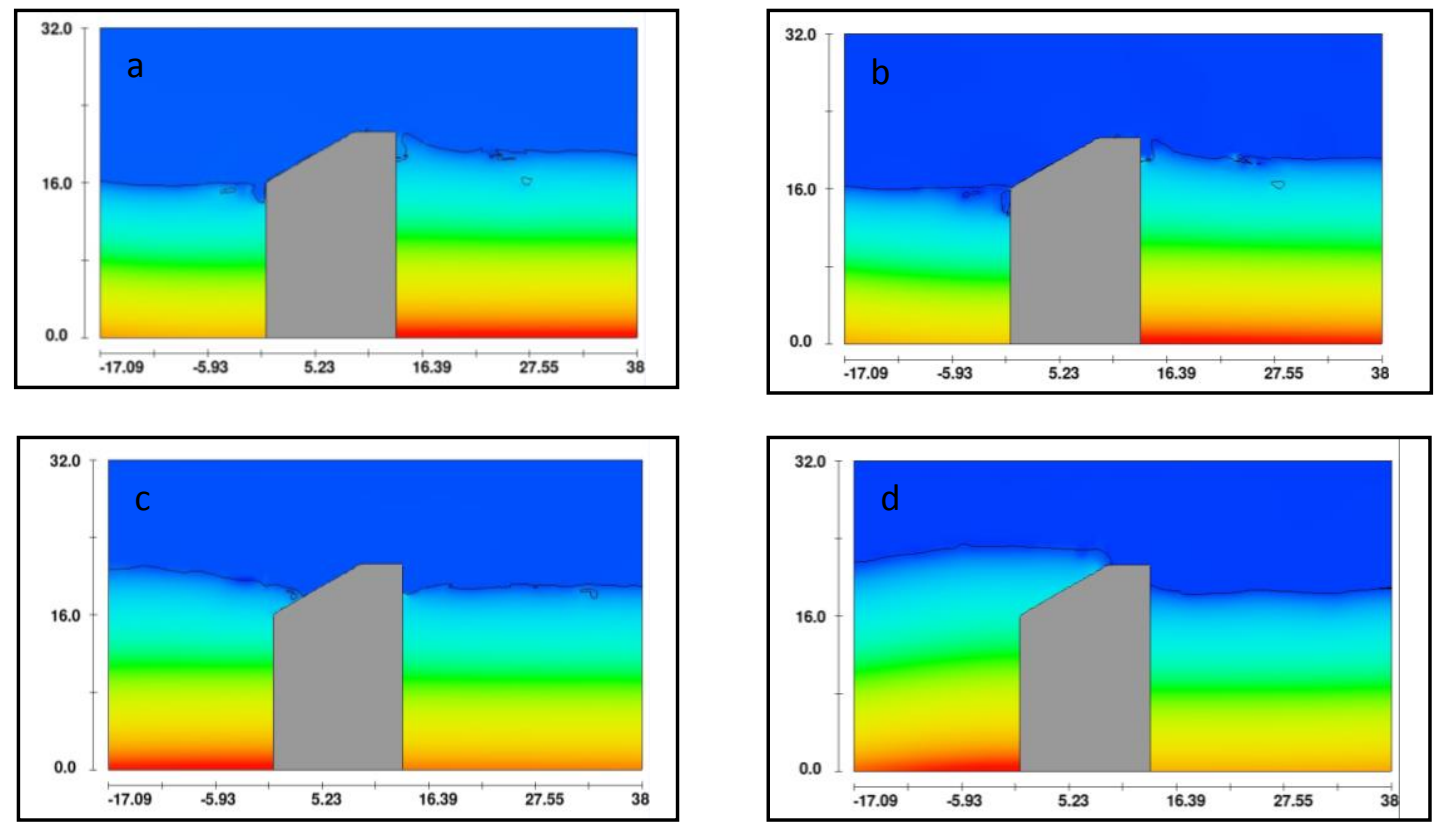

Figure 5. Example of surging breaker (Test 3A). 


\section{Analysis of Horizontal Force}

One of the most interesting features of the horizontal force signals is shown in Table 2, where it is seen that the average impulse per cycle is negative for all tests; this suggests a certain trend of the structure to slide seaward rather than landward. The observed behavior is clearly related to the occurrence of wave overtopping, which from the one side reduces magnitude and duration of the landward force, and from the other side increases the seaward loadings due to the action of transmitted waves.

\begin{tabular}{|c|c|}
\hline \multicolumn{2}{|c|}{ Table 2. Average impulse per cycle. } \\
\hline TEST CODE & Hs [m] \\
\hline 1A & -320.06 \\
1B & -272.56 \\
1C & -128.24 \\
2A & -1729.83 \\
2C & -674.19 \\
3A & -772.04 \\
3B & -275.13 \\
4A & -167.27 \\
\hline
\end{tabular}

In terms of force magnitude, it has been found out that the average seaward to landward force peak ratio decreases with growing period (Figure 6a), irrespective of the inclusion of air in the simulation. Same goes for the ratio between the maximum forces (Figure 6b) and for the percentage of waves for which the seaward force peak exceeds the landward one. (Figure 6c).
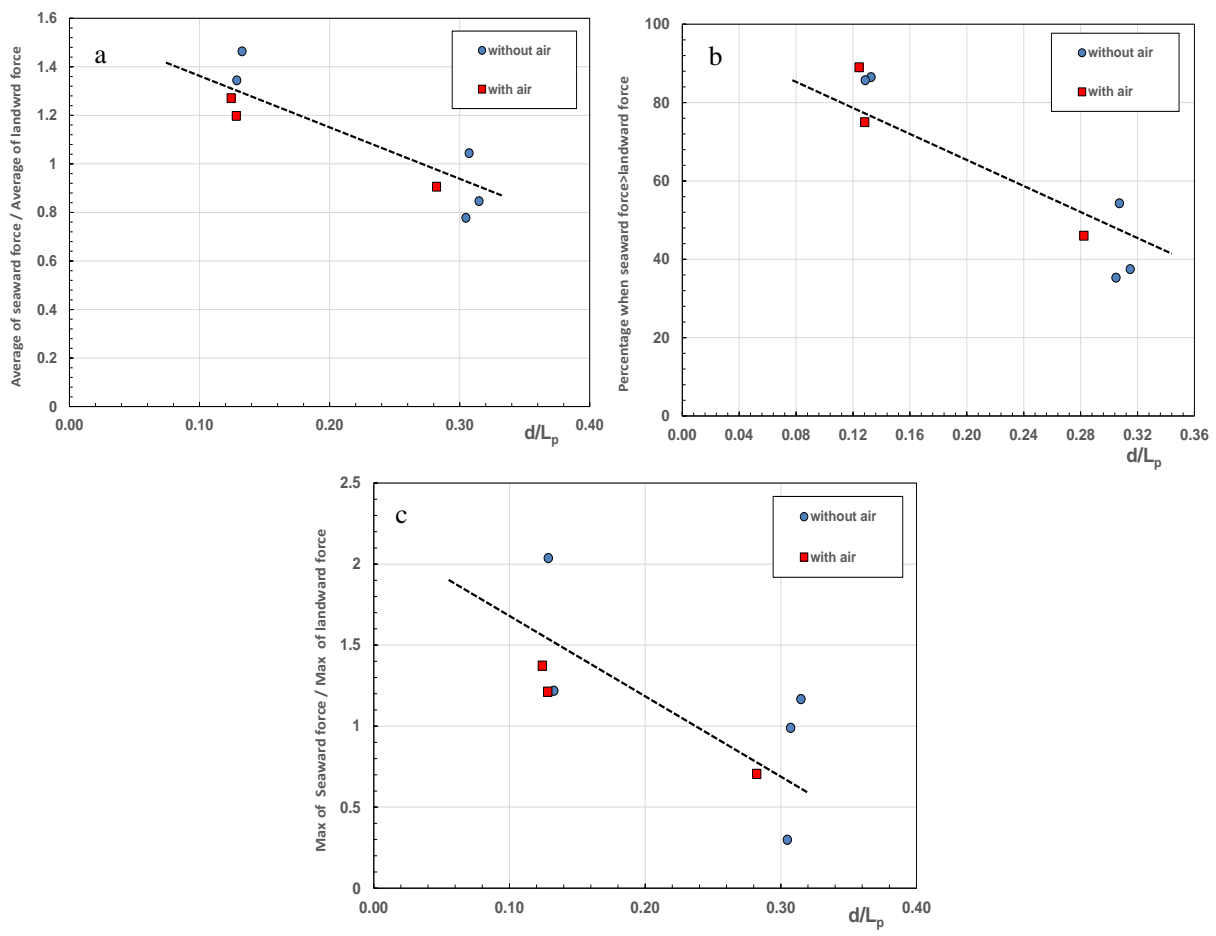

Figure 6. Effect of wave period on the characteristics of the horizontal force. a) Average seaward to landward force peak ratio; b) Ratio of the maximum seaward force peak to the maximum landward one; c) Percentage of waves for which the seaward force peak exceeds the landward one.

In other words, the larger the wave period the more significant seaward forces seem to be from an engineering point of view. In the next subsections, a detailed analysis of wave loadings is given, starting from those exerted onto the outer face of the wall; then, an insight on the role of wave overtopping is provided. 


\section{Horizontal Force on the outer face of the wall}

\section{Force under the uprush phase}

Figures 7 and 9 show the time histories of the horizontal wave force exerted on the outer face of the breakwater during the breaking events of Figures 3 and 4. In the former, it is seen that when the incoming wave plunges into the water just seaward the structure, an oscillation of the wave load is created at approximately $2.75 \mathrm{~Hz}$.

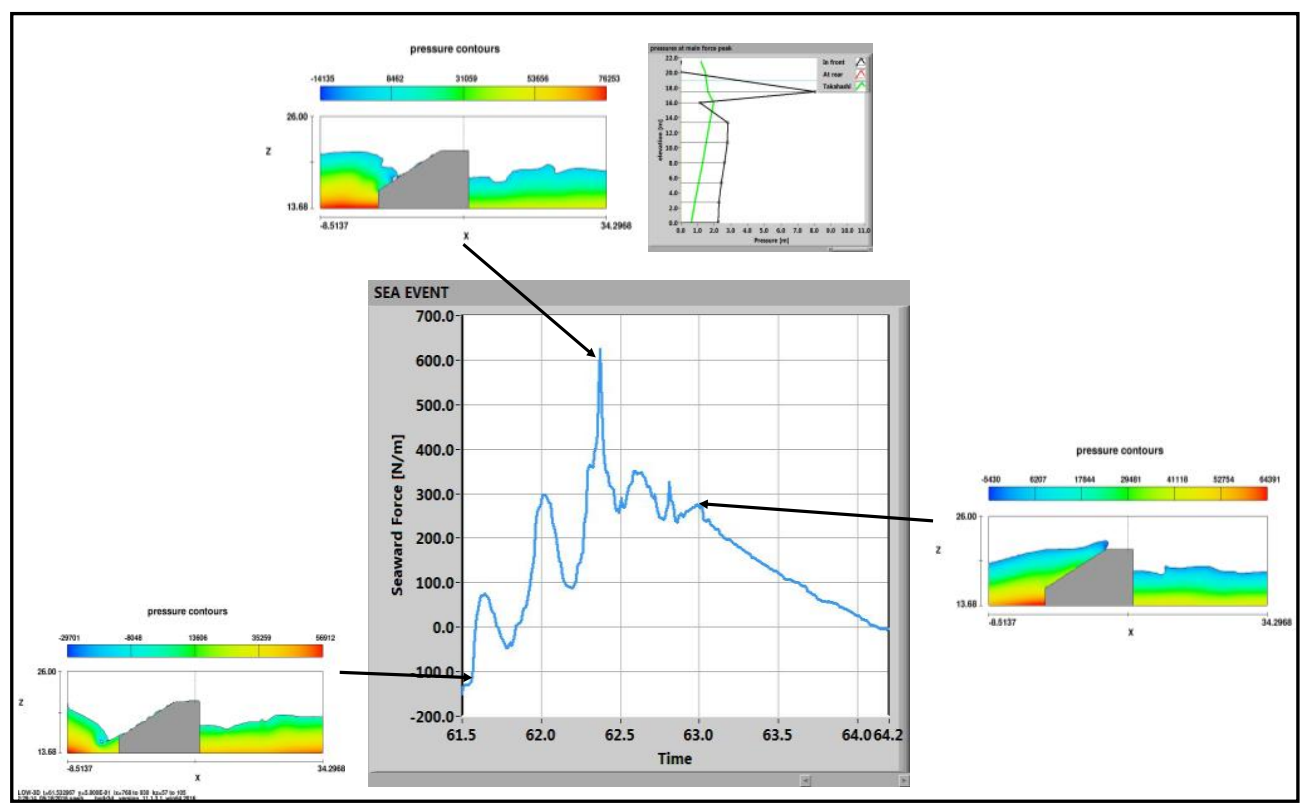

Figure 7. Time history of the horizontal force for the event of Figure 3

Then, when the plunging jets detaching from the reformed wave hit the slope, a sharp peak is created with a distribution of pressure (at the force maximum) similar to that described for impacting waves on conventional vertical breakwaters (Peregrine, 2003). In this regard, it is noteworthy that the measured pressures are significantly larger compared to the prediction of the Takahashi et.al method (reported in green in Figure 5). Finally, it is also of interest that the instant of incipient overtopping occurs when the force event is in a descending phase; this is explained by the fact that the force on the vertical part of breakwater and that on the sloping one are phase shifted, as pointed out by Takahashi et.al (1994).

Another beneficial consequence of the sloping top is shown in Figure 5, which shows the time history of the wave pressure at the location of the maximum of the distribution of Figure 4. It can be noticed from the lower right panel that the absolute peak of pressure is around $11 \mathrm{~m}$ of water column, whereas at the instant of maximum force it is reduced to $8 \mathrm{~m}$ that is nearly $30 \%$ less. 


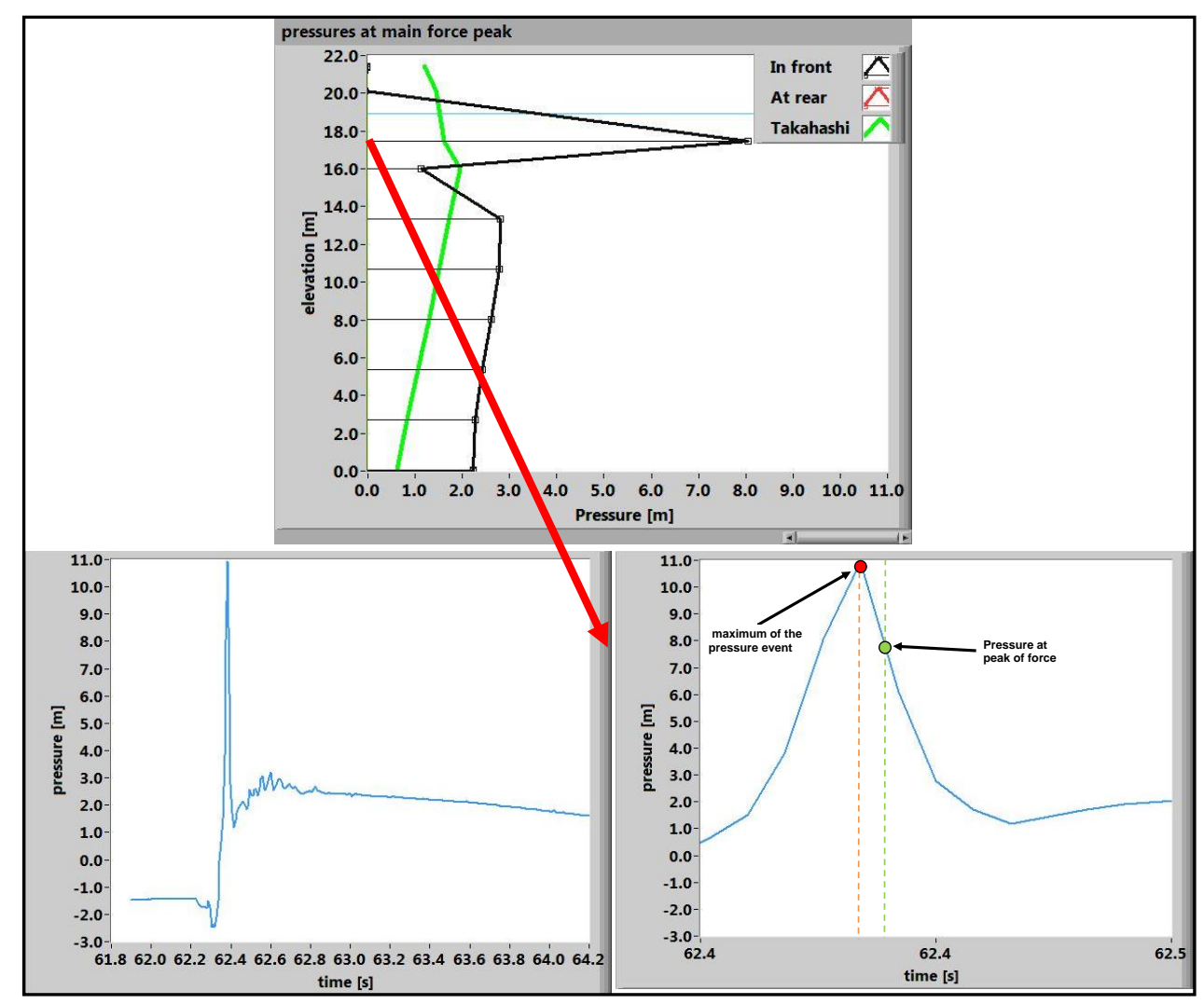

Figure 8. a: wave pressure distribution at the force peak of Figure 7 ; b: time history of the wave pressure at the location of the maximum in the distribution; c: zoom of the time history b, close to the peak.

The impact event of Figure 4 is reported in Figure 9. It is seen that the maximum of wave force corresponds to the occurrence of impulsive loadings close to the transducer S14, i.e. at the junction between the vertical and sloping part of the structure. A series of oscillations at approximately $3 \mathrm{~Hz}$ follow the wave slamming. However, the maximum pressure measured is of the order of two times the incident significant wave height, which is far less than what achieved on vertical breakwaters, where values exceeding ten have been reported (Goda, 1995). The predictions of Takahashi et.al method are seen to largely under predict experimental results.

In the event of Figure 5 (quasi standing wave/surging breaker with inclusion of air, the small impact occurring in the trough of the incident wave generates only a fast oscillation of the pressure chronograms at the locations S13 and S14 (Figure 10). The latter is basically due to the compression of the air pocket created between the plunging jet and the wall. As for the rest, the force time history is basically of pulsating type and the Takahashi et al formula gives safe predictions of wave pressures. Since the wavelength is large compared the length of the sloping top, the lag of phase of pressures between the lower and the upper part of the structure is small and the peak of force occurs approximately at the instant of incipient overtopping 


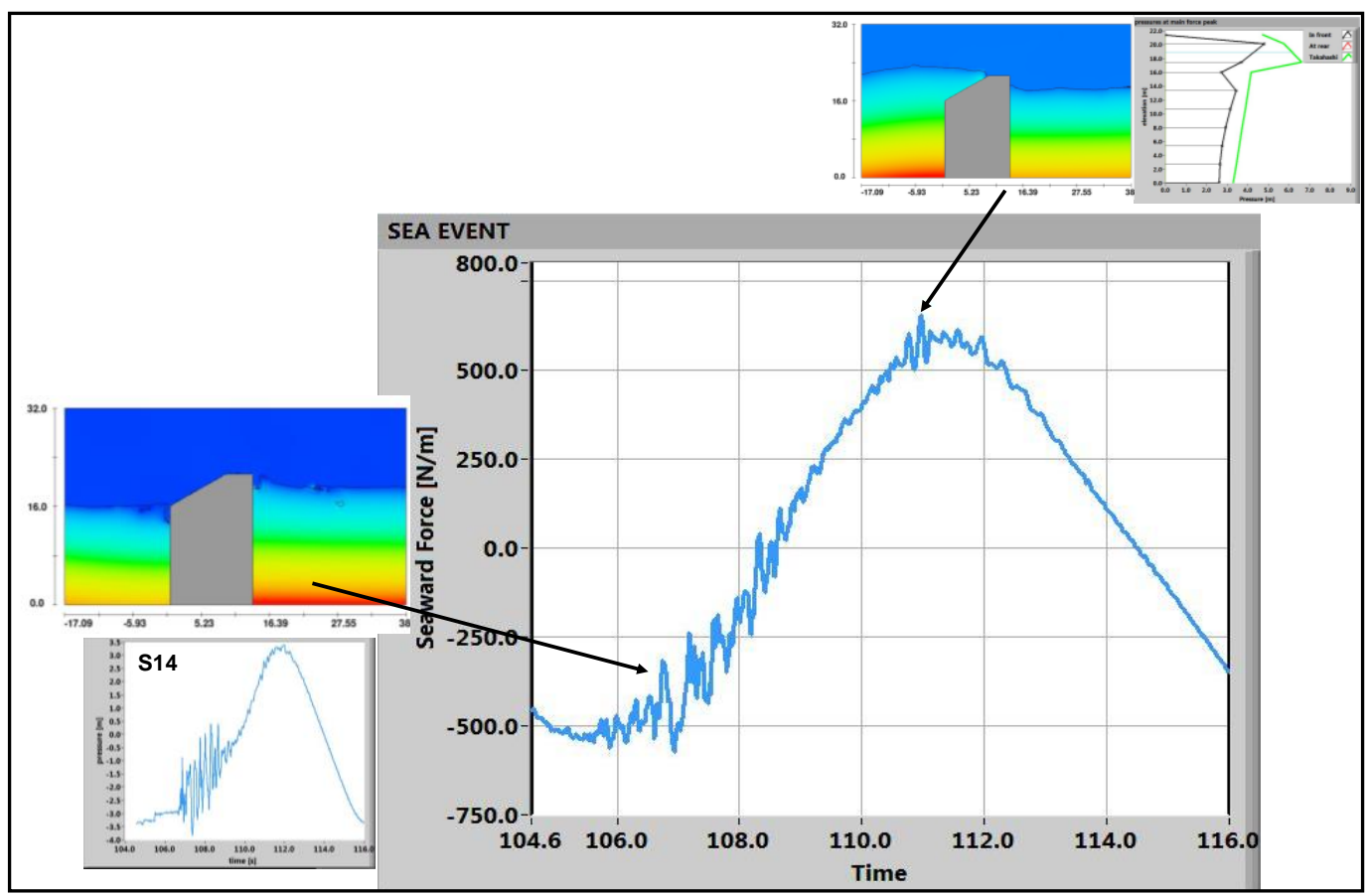

Figure 9. Time history of the horizontal force for the event of Figure 4

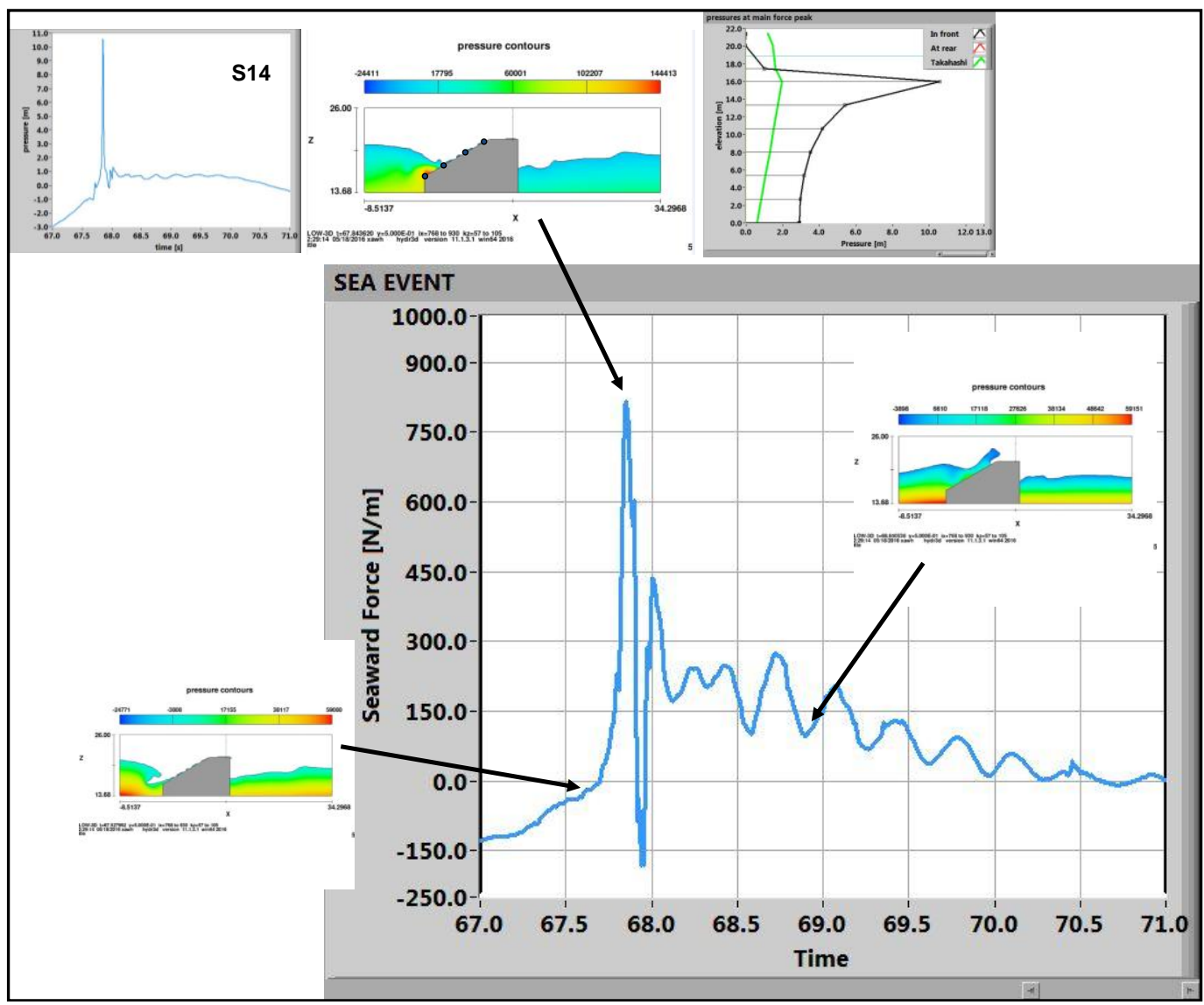

Figure 10. Time history of the horizontal force for the event of Figure 5 


\section{Global characteristics of wave loadings}

Figure 11 shows the maximum pressure measured on the outer face in each experiment, as a function of the relative water depth $\mathrm{d} / \mathrm{L}_{\mathrm{p}}$. It is seen that the experimental values range from 0.77 to 2.5 , tending to increase with reducing period. As anticipated, these values are significantly lower than those measured for non-overtopped vertical breakwaters under impact waves, where $\mathrm{p} / \mathrm{\rho g} \mathrm{H}_{\mathrm{s}}$ reached up to 50 (Vicinanza, 1997). Despite the few points available, air is seen to have a central effect (as expected), halving the breaking induced wave pressures.

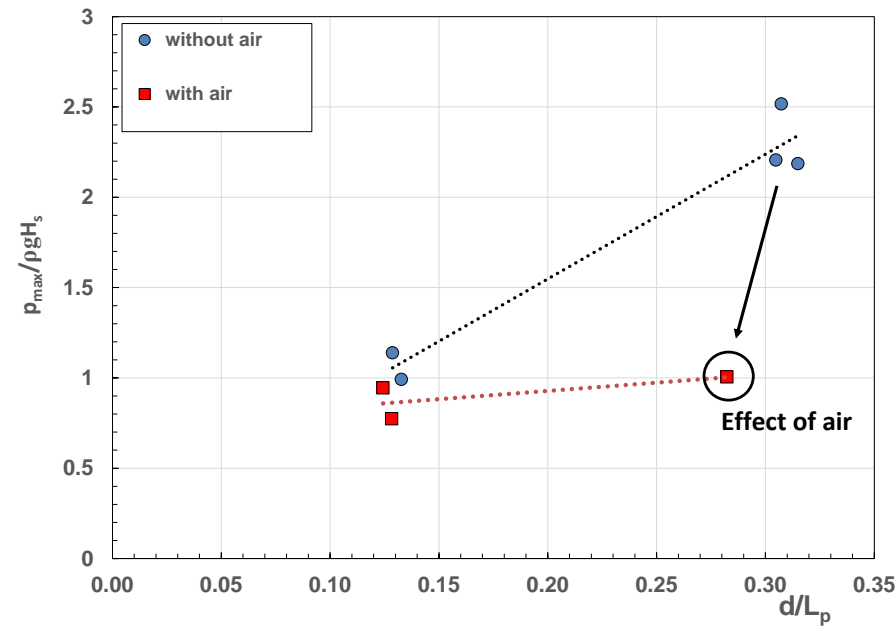

Figure 11. Maximum pressure measured on the front face (at the peak of force) as function of the relative water depth.

Figure 12 shows the ratio between the force predicted by the Takahashi et.al (1994) using the maximum wave height, and the maximum value of the measured landward peak of force (minimum safety factor). The formula would seem to underestimate experimental data with reducing wave period, although new experiments are needed to fill the gap in the interval $d / L_{p}=0.13-0.3$. It is worth noticing that under-predictions for short waves are not due to the local peaks caused by wave breaking; it is seen that even after smoothing such local spikes the Takahashi formula is exceeded, although the minimum safety factor increases (Figure 13).

An additional major concern is about seaward forces under trough condition. As stated above, even not considering the transmitted wave field, seaward forces tend to exceed the landward ones, whose magnitude is decreased by the overtopping occurrence. It has been found that for all the tests, the maximum measured trough forces significantly exceed the Takahashi predictions, with safety factors ranging from 0.85 to 0.4 . This would mean that in lack of an appropriate estimation of such loadings, the structure would tend to slide seaward even in cases where Takahashi formula provides safe values of the force under the crest conditions.

\section{Effect of the transmitted wave field}

The transmitted wave field is generally in phase opposition respect to the incoming waves and accordingly both the landward and the seaward force exerted on the outer face of the wall are amplified (e.g. Figure 14). The negative pressures exerted on the rear face of the breakwater under the crest (left panel of Figure 14), leads the total "net" wave load to exceed the predictions of Takahashi et.al method for all the tests here examined.

According to the observations of Walkden et.al (2001), it has been found wave overtopping may cause seaward directed impulsive loadings. 


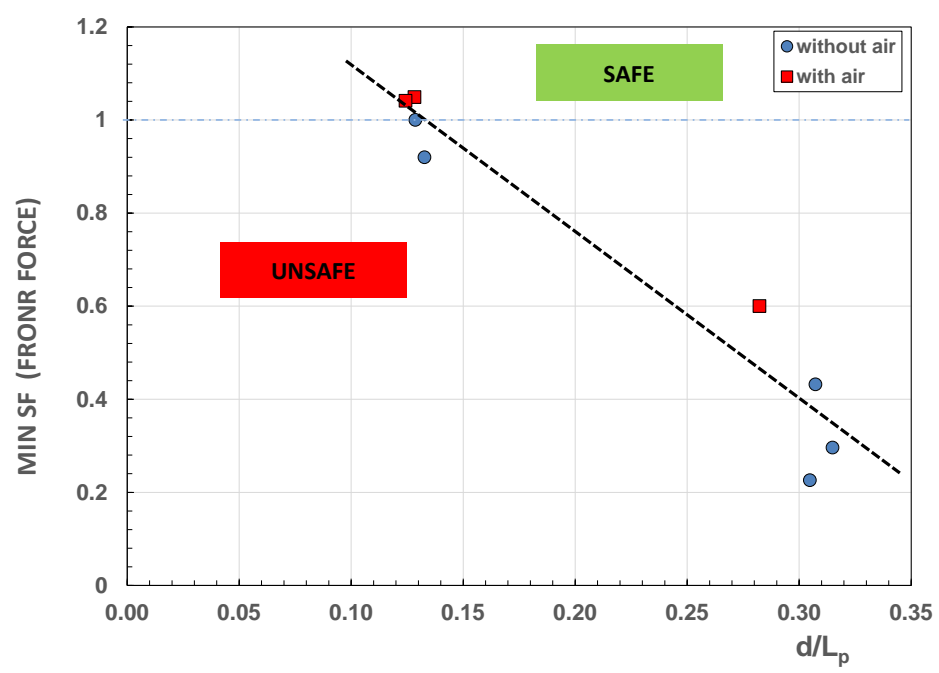

Figure 12. Minimum safety factor as a function of the relative water depth.
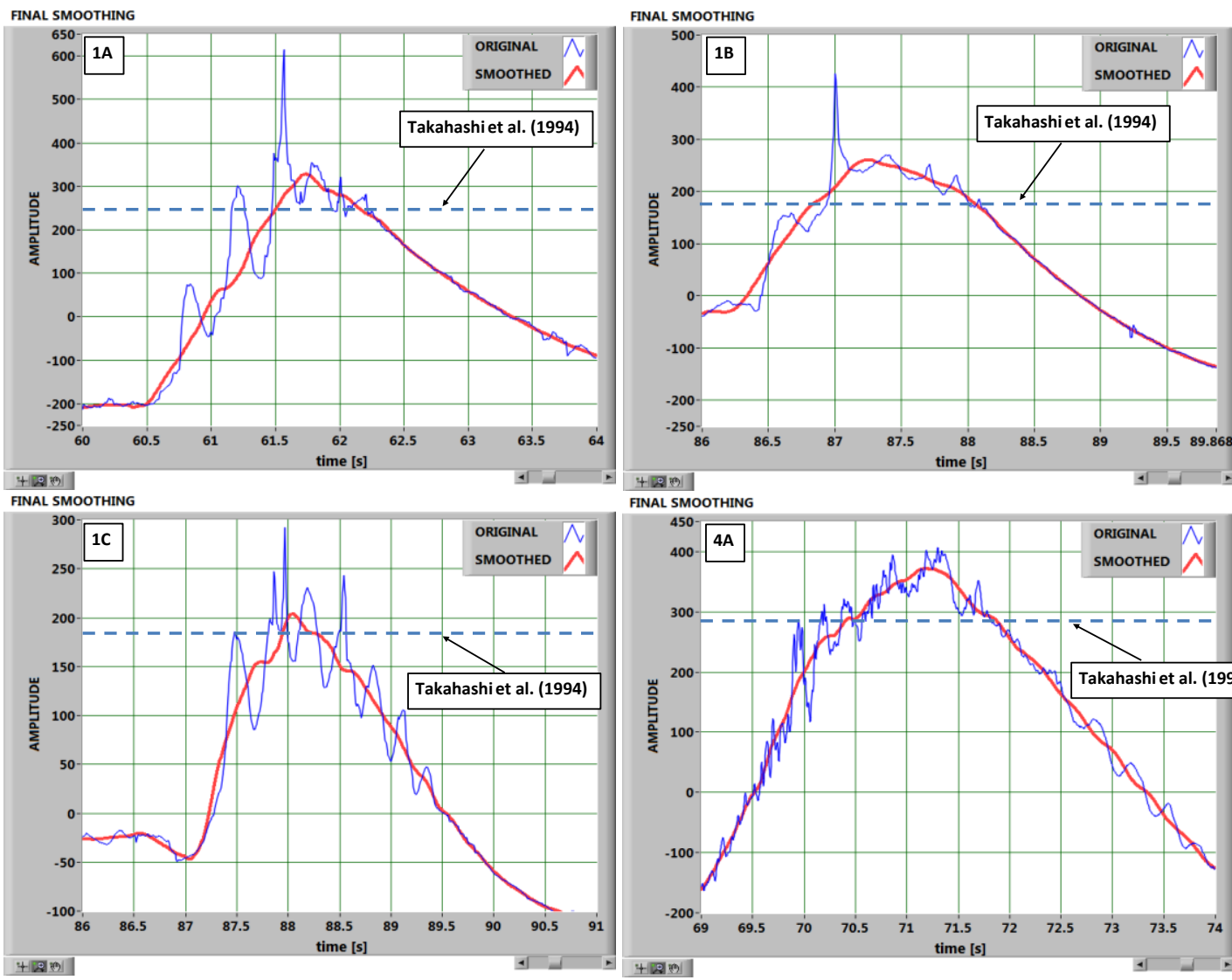

FINAL SMOOTHING

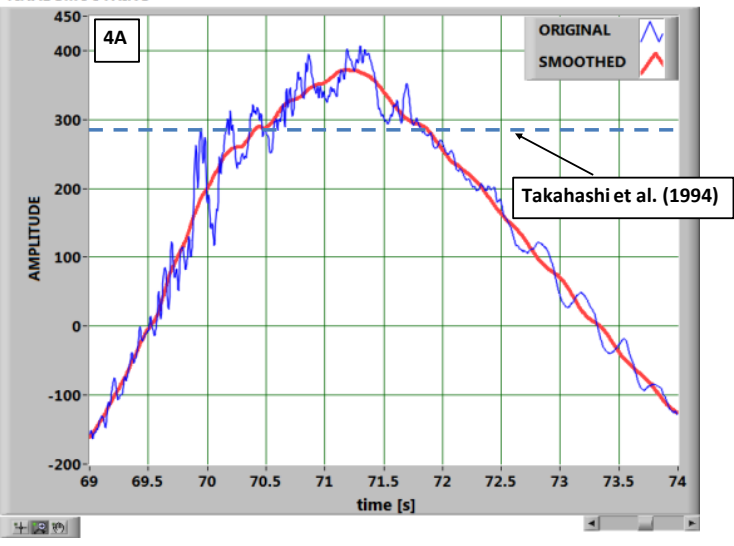

Figure 13. Comparison between Takahashi et al. predictions and experimental force peaks after smoothing the breaking induced peaks. 


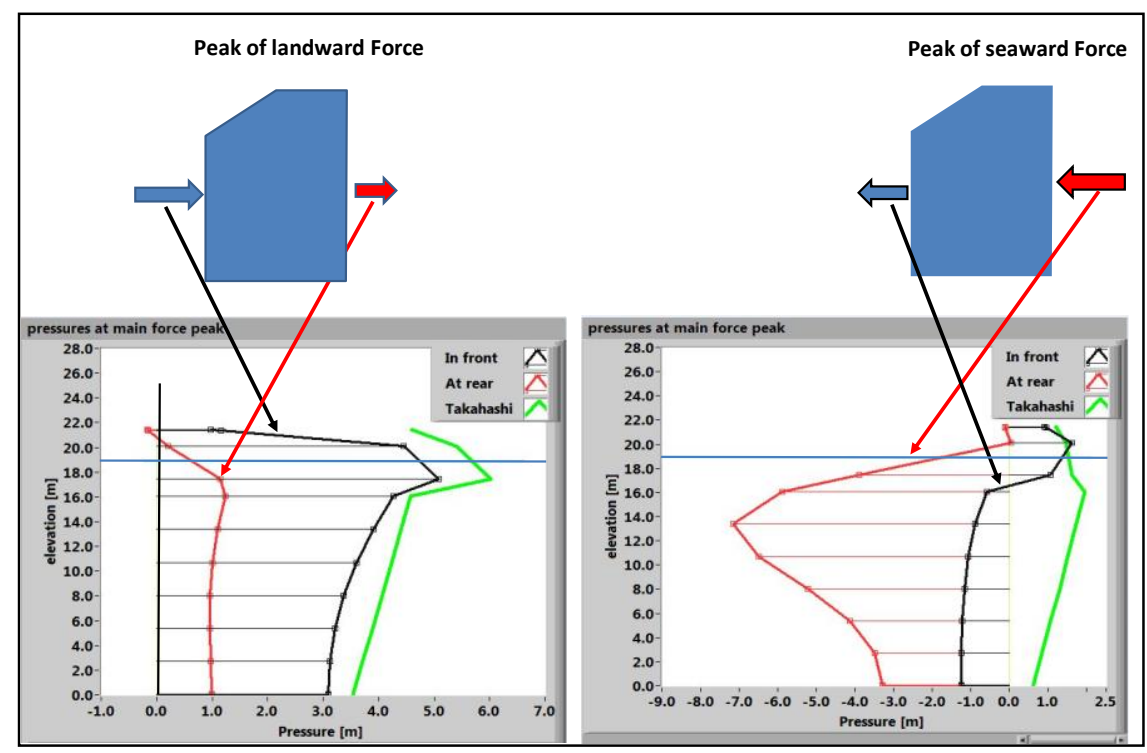

Figure 14. Effect of the transmitted wave pressures on the landward (left panel) and seaward (right panel) peak of force.

An example is given in the left panel of Figure 15, which refers to the test 1A, conducted without including the effect of air. The violent impact of the overtopping jet onto the water behind the structure generates large accelerations and inertia forces that are compensated by a system of impulsive pressures at the wall. The impact, which leads to maximum pressures of the order of two times the significant wave height, is followed by a series of free oscillations of the water surface at a frequency of about $3 \mathrm{~Hz}$.

As expected, the presence of a cushion of air between the overtopping jet and the rear wall, leads to a significant reduction of the main peak. This simply because part of the inertia force is absorbed as compression stress of the air pocket. As shown in the right panel of Figure 15, which refers to the test $4 \mathrm{~A}$ in this case a real impact event is actually scarcely recognizable.

In both the cases above presented, though, the pressure impulse associated with the peak of the force event is significantly under predicted by the method proposed by Walkden et al. in 2001 (Figure 16).

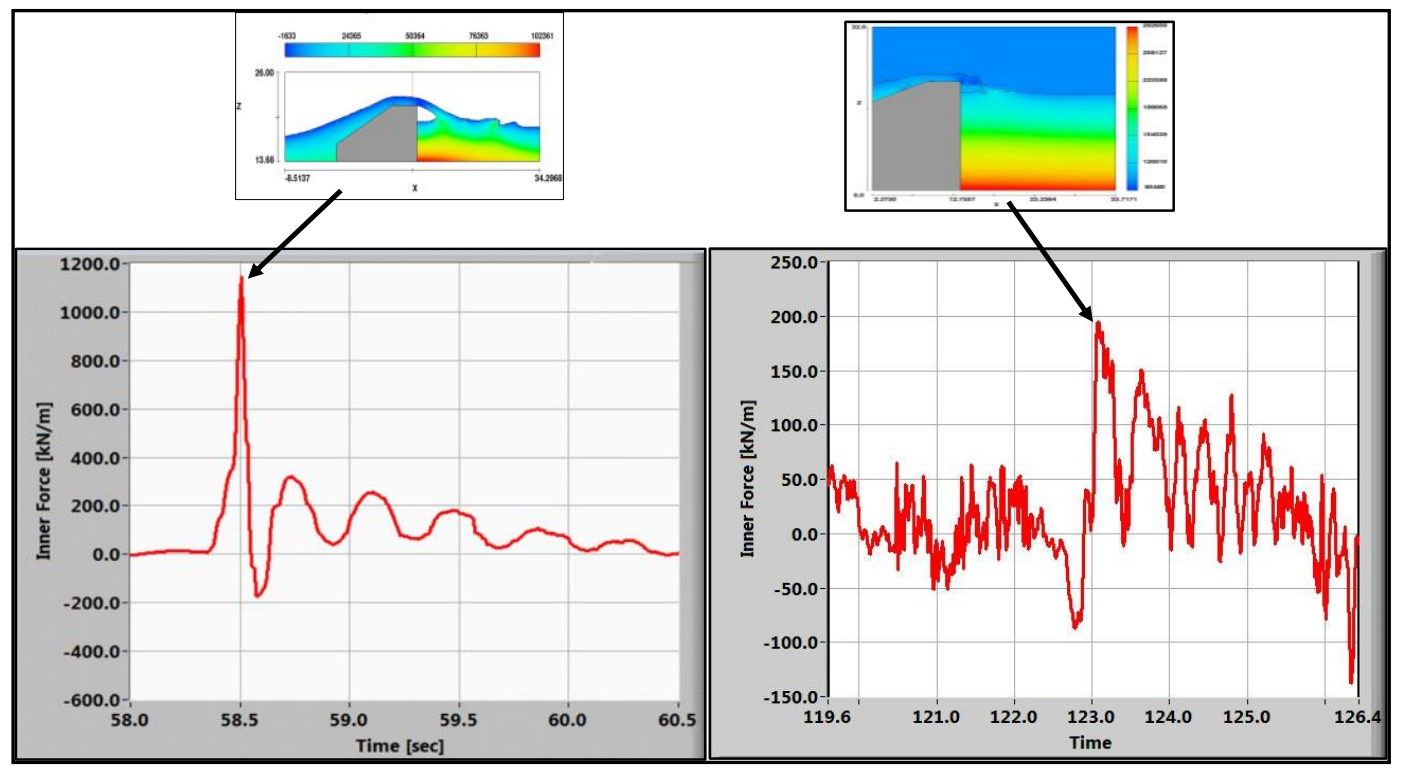

Figure 15. Examples of overtopping generated impact events. Left panel: test 1A, Right Panel: test 4A. 


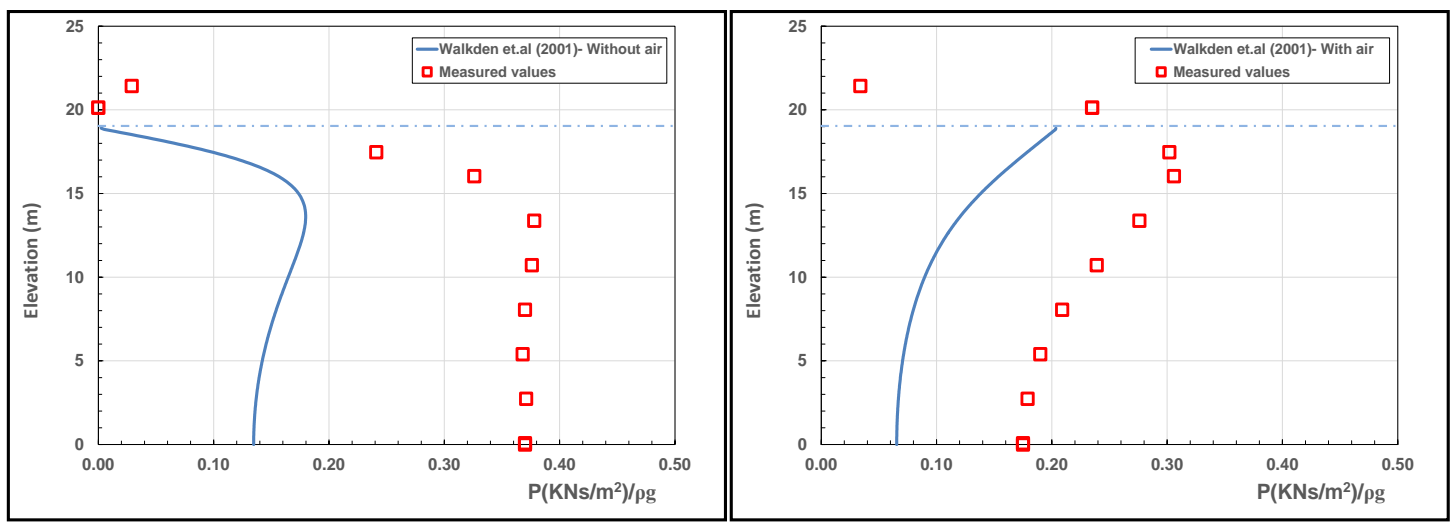

Figure 16. Comparison between measured pressure impulse at the force peak and predictions of Walkden et al. (2001)

\section{CONCLUSIONS}

In this paper the structural response of an overtopped sloping top caisson breakwater has been studied through 8 numerical CFD experiments conducted with Flow-3D. Five of these tests have been performed neglecting the presence of air, whereas in three of them it has been accounted for. The main conclusions of the analysis can be summarized as follows:

a. The wave overtopping causes a reduction of wave force under the crest phase and generates supplementary actions on the rear wall via transmission. As a result, the main hydrodynamic loadings are directed seaward rather than landward.

b. The method of Takahashi et al. (1994) for the prediction of the maximum force under the crest phase seem to under predict experimental data, especially for steep waves.

c. The forces acting on the front face of the breakwater and those exerted onto the rear wall are in phase opposition; accordingly, wave overtopping tends to increase both the landward and the seaward loadings.

d. The maximum pressures measured whether in front or at rear of the structure are of the order of 2 times the incident significant wave height; as expected, the presence of air reduce significantly the magnitude of loadings, halving the pressures induced by breaking waves.

e. The impact of the overtopping jet onto the water behind the breakwater may cause impulsive loadings onto the rear wall as observed by Walkden et al. (2001). However, the method proposed by the authors to predict the pressure impulse associated with such events has been found to under predict experimental data, regardless of the presence of air in the simulation.

\section{REFERENCES}

Allsop, N.W.H., J.E. McKenna, D.Vicinanza, and T.T.J. Whittaker. 1997. New design methods for wave impact loadings on vertical breakwaters and seawalls, Proceedings of the 25th International Conference on Coastal Engineering, 2, pp. 2508-2521.

Buccino, M.; Vicinanza, D.; Stagonas, D. 2015a. Development of a composite seawall wave energy conversion system. Renew. Energy 2015, 81, 509-522.

Buccino, M., Vicinanza, D., Dalerno, D., Banfi, D., Calabrese, M. 2015b. Nature and magnitude of wave loadings at Sea-wave Slotcone Generators". Ocean Engineering. 95, 34-58.

Buccino, M., Dentale, F., Salerno, D., Contestabile, P., Calabrese, M., 2016. the use of CFD in the analysis of wave loadings acting on seawave slot-cone generators. Sustainability, 2016, 8, 1255.

Calabrese, M., Buccino, M., Pasanisi, F., 2008. Wave breaking macrofeatures on a submerged rubble mound breakwater. Journal of Hydro-Environment Research, 1 (3-4), 216-225.

Cooker, M.J., Peregrine, D.H., 1995. Pressure-impulse theory for liquid impact problems. J. Fluid Mechanics, 297, 193-214. 
Dentale, F., Donnarumma, G., Pugliese Carratelli, E., 2014a. Simulation of flow within armour blocks in a breakwater. J. Coast. Res. 2014, 30, 528-536.

Dentale, F., Donnarumma, G., Pugliese Carratelli, E., 2014b. Numerical wave interaction with Tetrapods breakwater. J. Naval Arch. Ocean Eng. 2014, 6, 800-812.

Flow Science Inc., 2009. Suite Flow 3D. Flow Science Inc.: Santa Fe, Mexico.

Goda, Y., 1995. Japan's design practice in assessing wave forces on vertical breakwaters, Wave forces on inclined and vertical wall structures. ASCE $p .402$.

Peregrine, D.H., 2003. Water-wave impact on walls. Ann. Rev. Fluid Mech. 35, 23-44.

EurOtop. (2007). European manual for the assessment of wave overtopping, T. Pullen, N. W. H. Allsop, T. Bruce, A. Kortenhaus, H. Schüttrumpf, and J. W. Van der Meer, eds., HR Wallingford, Wallingford, U.K.

Takahashi, S. Hosoyamada, S. Yamamoto, S., 1994. Hydrodynamic characteristics of sloping top caissons. In Proceedings of International Conference on HydroTechnical Engineering for Port and Harbor Construction, 1. Port and Harbour; Research Institute: Tokyo, Japan, 1994; pp. 733-746.

Vicinanza, D., 1997. (In Italian). Ph.D. thesis). Pressioni e forze di impatto di onde frangenti su dighe a paramento verticale e composite.

Vicinanza, D., Dentale, F., Salerno, D., Buccino, M., 2015. Structural response of Seawave Slot-Cone Generator (SSG) from Random Wave CFD simulations. Proceedings of the International Offshore and Polar Engineering Conference (ISOPE 2015). 2015-January, pp. 985-991.

Walkden, M., Wood, D., Bruce, T., and Peregrine, D. (2001) Impulsive seaward loads induced by wave overtopping on caisson breakwaters. Coastal Engineering, 42, 257-276.

Zelt, J.A., Skjelbreia, J.E, 1992. Estimating incident and reflected wave field using an arbitrary number of wavegauges. In Proceedings of the International Conference on Coastal Engineering, Venice, Italy, 4-9 October 1992; pp. 777-789. 